\title{
Current approaches to enhance CNS delivery of drugs across the brain barriers
}

This article was published in the following Dove Press journal:

International Journal of Nanomedicine

10 May 2014

Number of times this article has been viewed

\author{
Cui-Tao Lu' \\ Ying-Zheng Zhao 2,3 \\ Ho Lun Wong ${ }^{4}$ \\ Jun $\mathrm{Cai}^{5}$ \\ Lei Peng ${ }^{2}$ \\ Xin-Qiao Tian'
}

'The Second Affiliated Hospital of Wenzhou Medical University, Wenzhou City, Zhejiang Province, People's Republic of China; ${ }^{2}$ Hainan Medical College, Haikou City, Hainan Province, People's Republic of China; ${ }^{3}$ College of Pharmaceutical Sciences, Wenzhou Medical University, Zhejiang Province, People's Republic of China; ${ }^{4}$ School of Pharmacy, Temple University, Philadelphia, PA, USA; ${ }^{5}$ Departments of Pediatrics and Anatomical Sciences and Neurobiology, University of Louisville School of Medicine Louisville, KY, USA

Correspondence: Ying-Zheng Zhao Hainan Medical College, Haikou City, Hainan Province 325035,

People's Republic of China

Email pharmtds@163.com

Xin-Qiao Tian

The Second Affiliated Hospital of

Wenzhou Medical University, Wenzhou

City, Zhejiang Province 325000,

People's Republic of China

Email tianxq2005@163.com

\begin{abstract}
Although many agents have therapeutic potentials for central nervous system (CNS) diseases, few of these agents have been clinically used because of the brain barriers. As the protective barrier of the CNS, the blood-brain barrier and the blood-cerebrospinal fluid barrier maintain the brain microenvironment, neuronal activity, and proper functioning of the CNS. Different strategies for efficient CNS delivery have been studied. This article reviews the current approaches to open or facilitate penetration across these barriers for enhanced drug delivery to the CNS. These approaches are summarized into three broad categories: noninvasive, invasive, and miscellaneous techniques. The progresses made using these approaches are reviewed, and the associated mechanisms and problems are discussed.
\end{abstract}

Keywords: drug delivery system, blood-brain barrier (BBB), central nervous system, braintargeted therapy, cerebrospinal fluid (CSF)

\section{Introduction}

Systemic drug treatment of neurological diseases, such as brain tumors, inborn metabolic errors (eg, lysosomal storage diseases), and infectious and neurodegenerative diseases, is a daunting challenge due to the unique protective barriers of the central nervous system (CNS) ${ }^{1,2}$ Such innate barriers, mainly the blood-brain barrier (BBB) and the blood-cerebrospinal fluid (CSF) barrier (BCSFB), not only play a critical role in protecting the CNS against toxic and infectious agents while maintaining the ionic and volumetric environments, but also create an obstacle for effective systemic drug delivery to the CNS. The BBB consists of the tight junctions (TJs) of capillary endothelial cells on one side and the foot processes of astrocytes on the other side, whereas the BCSFB is formed by the TJs of choroid plexus cells surrounding the microvascular endothelium with intracellular gap and fenestration (Figure 1). Although the BBB and BCSFB exert different principal functions in terms of the structural difference, ${ }^{3,4}$ they both participate in controlling the transfer of molecules between the blood and brain parenchyma or CSF.

Under the physiological condition, circulating molecules can only gain access to brain or CSF via a transcellular route through the capillary endothelial cells or choroid plexus cells by either passive or active transport or both. Free diffusion is the main passive pathway. Generally, only lipid soluble (lipophilic) molecules with a molecular mass under 400-600 Da can go through the cells with TJs. Other molecules may hurdle via certain endogenous transport systems of the cells mostly through carrier-mediated transport, ${ }^{5}$ receptor-mediated transport, or absorptive-mediated transport. ${ }^{6}$ With these transport systems, essential nutrients including amino acids, glucose, carboxylic acids, and 


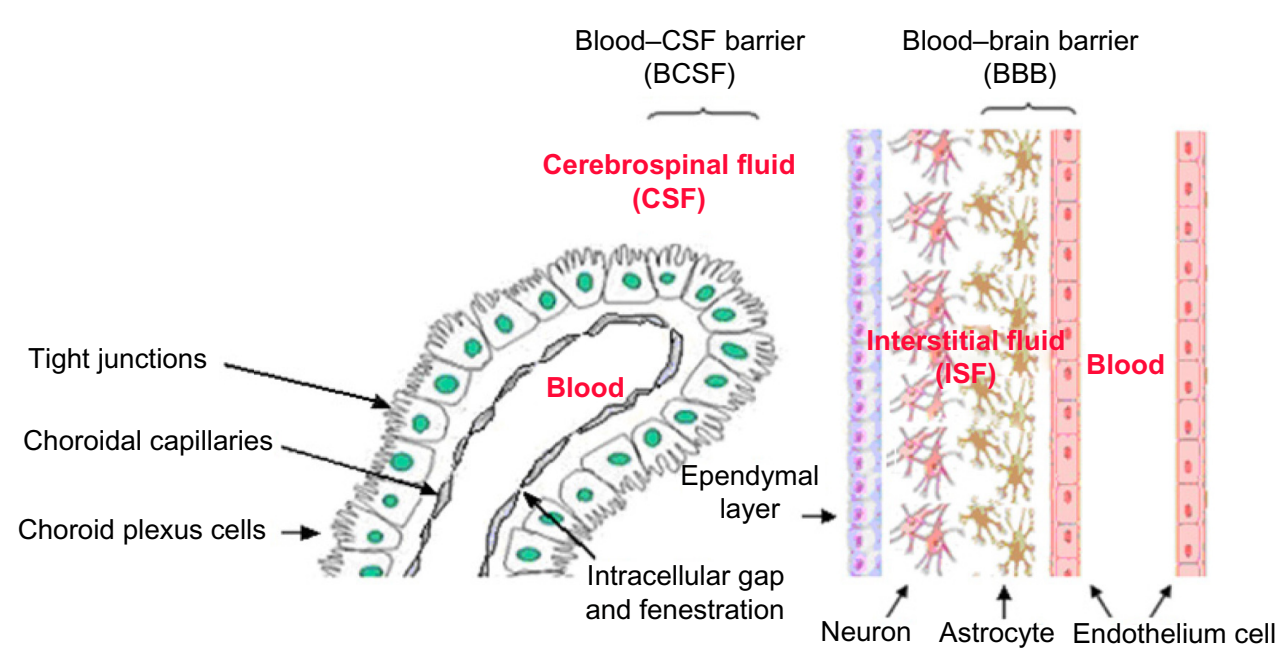

Figure I Overview of the blood-brain barrier and blood-cerebrospinal fluid barrier.

nucleosides can diffuse into the brain. The receptor-mediated transport mechanism facilitates transport of macromolecules conjugated with surface receptor ligands such as transferrin, lactoferrin, and insulin. Absorptive-mediated transport is a type of endocytosis induced by the substance with cationized ligands or peptides such as albumin (Figure 2).

Active transport is the movement of all types of molecules across a cell membrane against its concentration gradient with cellular energy consumption (eg, adenosine triphosphate). Active transport can accumulate high concentrations of molecules in the cell, in which the transporters such as P-glycoprotein, multidrug-resistant protein, multidrug resistance-associated protein, system L-transporters, organic anion transporter, organic cation transporter, monocarboxylate transport system, concentrative nucleoside transporter, equilibrative nucleoside transporter, and peptide transport system-1 may participate. ${ }^{7-11}$

Considering special cellular structures of protective barriers, CNS drug discovery has to merge drug design or modification with the development of efficient delivery systems. Drug access directly into the brain has been extensively investigated during the last decade and has made marked progress recently. In this review, we integrate the current findings in the field of CNS delivery of drugs. The mechanisms and issues involved in these strategies are also discussed.

\section{Current approaches for enhanced drug delivery to the CNS}

As shown in Table 1, many factors can affect the transport of therapeutics across the BBB and the BCSFB.

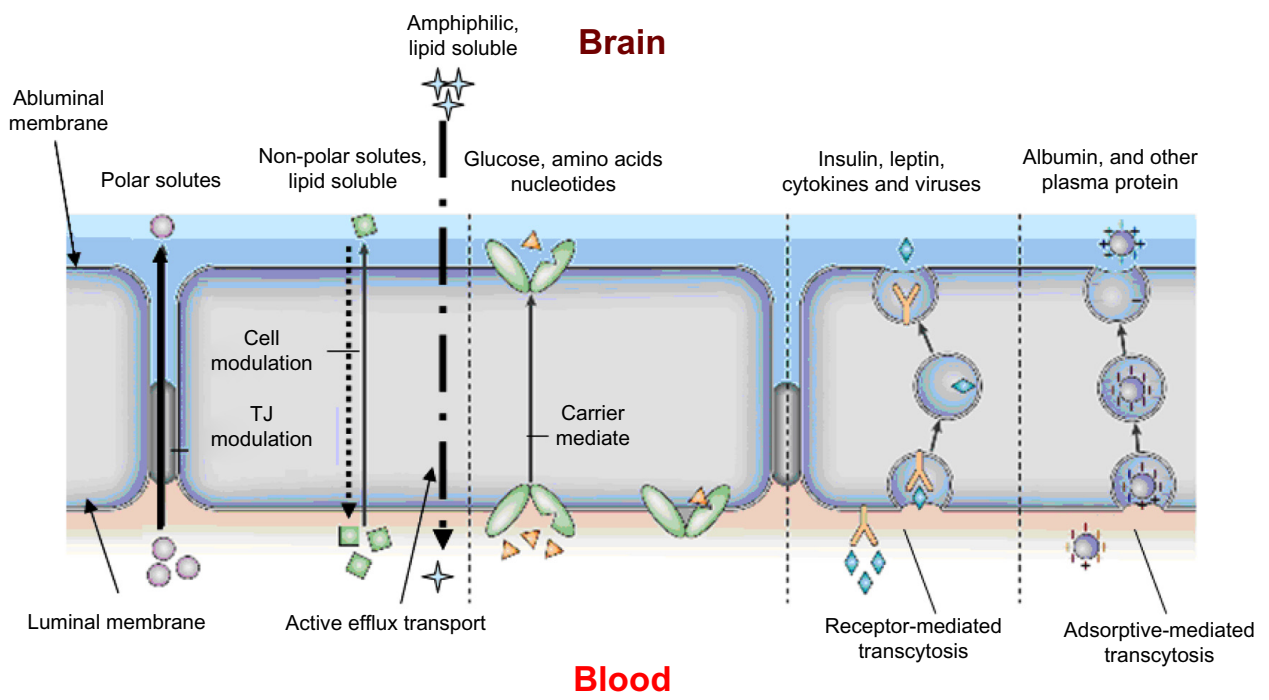

Figure 2 Potential transport mechanisms across the blood-brain barrier. Diffusion and active transport are the main transport mechanisms. Abbreviation: TJ, tight junction. 
Table I Factors affecting the therapeutics across the BBB and the BCSFB

\begin{tabular}{|c|c|c|c|}
\hline $\begin{array}{l}\text { Physiochemical } \\
\text { properties of the drugs }\end{array}$ & $\begin{array}{l}\text { Biopharmaceutic and } \\
\text { pharmacokinetic factors }\end{array}$ & Dosage form factors & Biological factors \\
\hline Lipophilicity & Systemic absorption & $\begin{array}{l}\text { Preparation, formulation } \\
\text { and additional agents }\end{array}$ & $\begin{array}{l}\text { Physiological characteristics } \\
\text { of the site of administration }\end{array}$ \\
\hline Molecular weight & Membrane transport & $\begin{array}{l}\text { Concentration gradient } \\
\text { of drug/polymer }\end{array}$ & Cerebral blood flow \\
\hline Molecular charge & $\begin{array}{l}\text { Affinity for receptors, efflux } \\
\text { proteins (eg, Pg-p) and carriers }\end{array}$ & $\begin{array}{l}\text { Particle size, flexibility, } \\
\text { and permeability }\end{array}$ & Pathological status \\
\hline Chemical structure & Distribution & Dissolution rate & \\
\hline Chemical conformation & Metabolism mechanism & & \\
\hline Polymorph & Clearance rate & & \\
\hline
\end{tabular}

Abbreviations: BBB, blood-brain barrier; BCSFB, blood-cerebrospinal fluid barrier; Pg-p, p-glycoprotein.

Generally, most therapeutics of CNS diseases in conventional administration enter the CNS via the systemic blood circulation. To reach effective drug concentrations at the CNS disease sites, it is necessary to raise the systemic drug levels by substantially enhanced dose or extended administration. This often significantly increases the risk of systemic toxicity. Therefore, researchers look for more ways to transfer therapeutic agents into the CNS without the need for increasing the systemic levels of these agents. Until now, three broad categories - noninvasive, invasive, and miscellaneous techniques - have been developed to enhance drug delivery to the CNS (Figure 3).

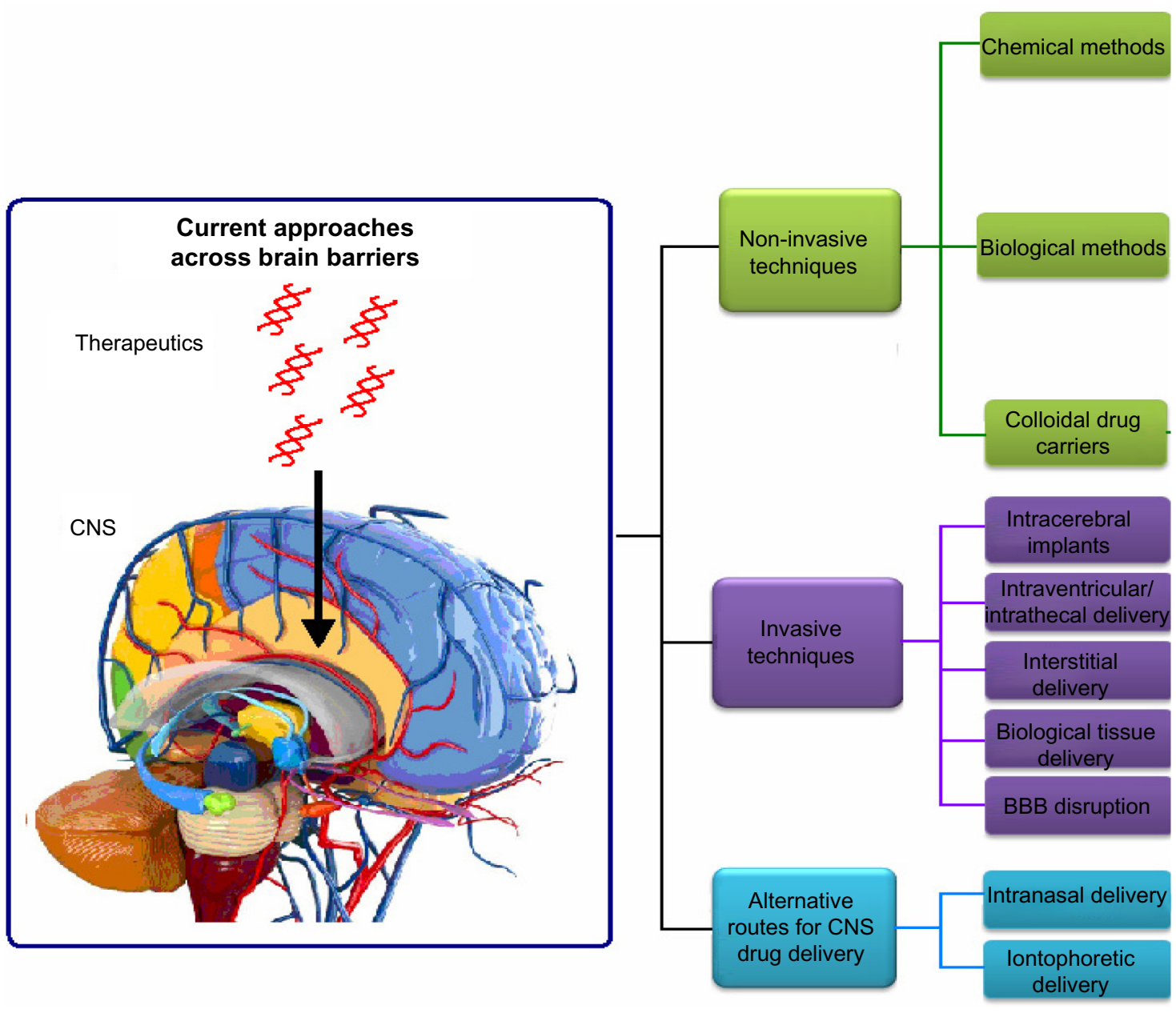

Figure 3 Current approaches for CNS drug delivery. Abbreviation: CNS, central nervous system. 


\section{Noninvasive techniques \\ Chemical approaches}

Chemical approaches rely on chemical structure transformation of drugs to improve their unsatisfactory physicochemical properties (such as solubility or membrane penetration) and therefore change their functionalities.

\section{Lipophilic analogs}

Since lipid solubility is a key factor in passive diffusion into the BBB, chemical modification of the drug itself into a more lipophilic form (lipidization) has been pursued. In lipidization, lipid groups are added to the polar ends of drug molecules to assemble into lipophilic analogs, which have better cerebrovascular permeability than the original drug. According to previous studies, ${ }^{3}$ lipophilic analogs with $\log \mathrm{P}$ (P: octanol-water partition coefficient) value in the range of 1.5-2.5 have good CNS permeability. A lot of acid-containing drugs have been explored by such approaches.

The main limitations of lipophilic analogs include low selectivity of drug molecules and poor tissue distribution. In addition, the lipidization strategy requires modification of lipid-like molecules into the hydrophilic part of the drug structure. Passive diffusion is generally considered as the main mechanism across the BBB for lipophilic molecules. However, the volume of distribution is generally enhanced with the lipidization of molecules, particularly when these molecules can bind plasma proteins in blood circulation. In addition, lipophilic analogs can affect the rate of oxidative metabolism by cytochrome P-450 enzymes and other enzymes. So the advantages of lipophilic analogs for brain delivery might be offset by the change of drug pharmacokinetic parameters. ${ }^{14}$

\section{Prodrugs}

Prodrugs are defined as compounds that, on administration, must undergo chemical conversion by metabolic processes before becoming an active pharmacological agent (Figure 4). ${ }^{12}$

With chemical modification, the prodrug method is used to make a drug more lipophilic. For example, morphine cannot enter the CNS by itself. After latentiation via acetylation of both hydroxyl groups, morphine can easily traverse the BBB and reach an effective concentration in brain. ${ }^{13}$

However, care should be taken before using the prodrug method because some prodrug molecules may alter the original tissue distribution, and the efficacy and toxicity of the parent drug.

\section{Chemical drug delivery system}

The chemical drug delivery system (CDS) term was first introduced by Bodor. ${ }^{14}$ Different from the prodrug approach, a CDS typically requires only a single activation step. However, more and more sophisticated prodrugs nowadays are activated in multiple steps.

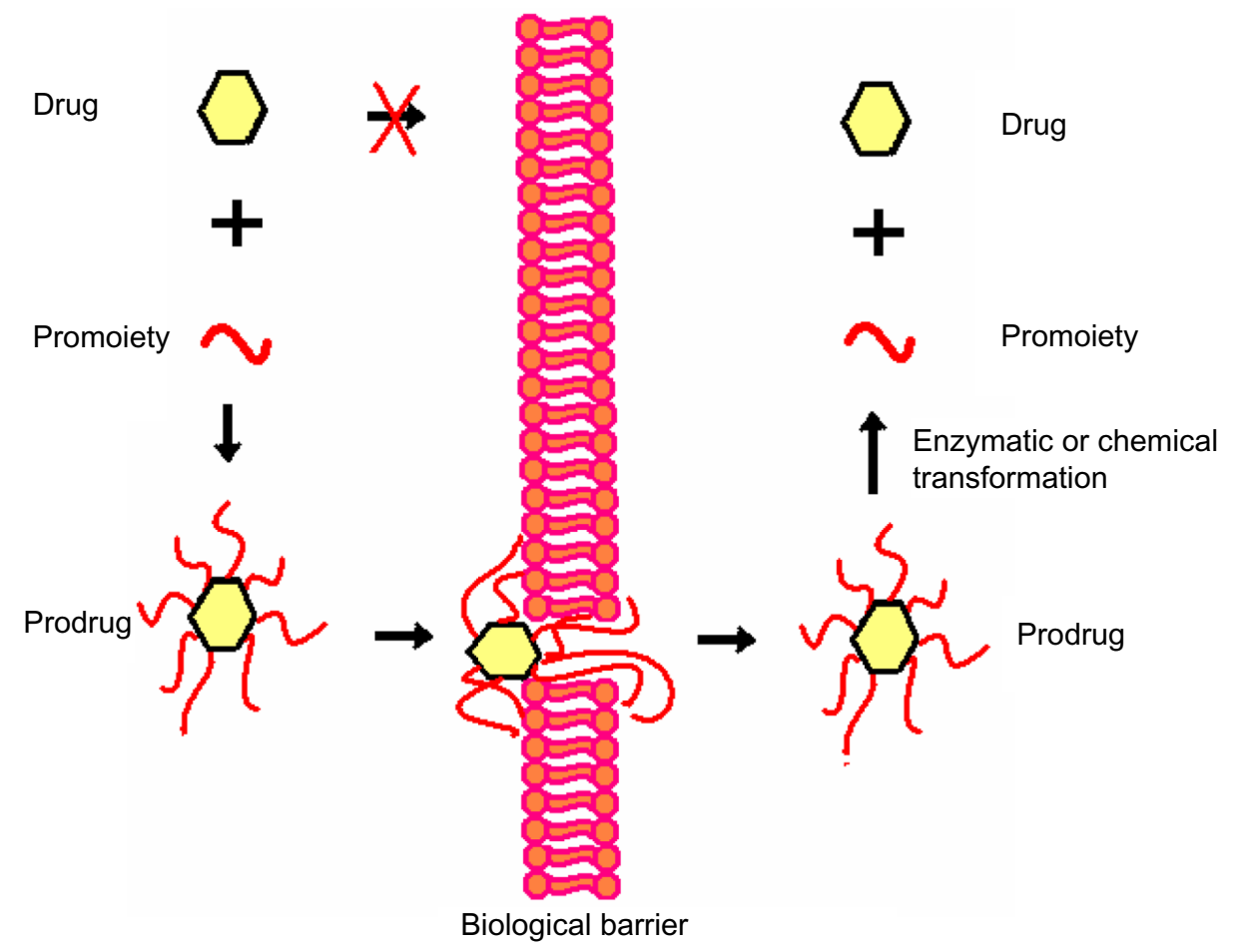

Figure 4 Illustration of the prodrug approach. 
Three types of CDS have been most investigated: 1) enzymatic physicochemical CDS, 2) site-specific enzymeactivated CDS, and 3) receptor-based CDS. As shown in Figure 5, 1,4-dihydro-N-methylnicotinic acid (dihydrotrigonelline) is a commonly used lipophilic targetor moiety that can increase the brain distribution of a wide variety of drugs. ${ }^{14-19}$

\section{Molecular packaging}

To enhance penetration of peptides through the BBB, the "molecular packaging" strategy has been developed. With molecular packaging, three goals can be simultaneously accomplished for enhanced BBB penetration: 1) increased lipophilicity to enhance passive transport, 2) prevention of premature degradation by increasing enzymatic stability, and 3) exploitation of the lock-in mechanism to provide targeting. In molecular packaging, the peptide unit is a part of a bulky molecule, dominated by the groups that prevent recognition by peptidases and direct BBB penetration. ${ }^{4}$

Some peptide drugs, such as DADLE (Tyr-D-Ala-GlyPhe-D-Leu) and thyrotropin-releasing hormone, ${ }^{20,21}$ have been reported using the molecular packaging strategy for brain delivery.

\section{Biological approaches}

Biological approaches of drug CNS delivery primarily emanate from the understanding of the physiological and anatomical nuances of the BBB transportation.

\section{Receptor/vector-mediated delivery of chimeric peptides}

The receptor/vector-mediated delivery of chimeric peptides strategy is based on using the coupling of a non-transportable peptide pharmaceutical to a transportable peptide or protein, which undergoes receptor-mediated or absorptive-mediated transcytosis through the BBB. ${ }^{22}$

Endocytosis can be triggered after binding of the vector to its receptor on the luminal surface of brain capillary endothelial cells. Following transport of the peptide across the cells and exocytosis at the abluminal plasma membrane, the peptide is released into brain interstitial space. Enzymatic cleavage may occur at the cleavage linkage between the vector and the drug to release the pharmacologically active moiety of the chimeric peptide.

A most recent finding indicated that the efficiency of receptor-mediated transcytosis across the $\mathrm{BBB}$ can be manipulated by tuning the nanoparticle (NP) avidity to the targeted receptor. ${ }^{23}$ In Wiley et al's study using gold NPs decorated with transferrin, ${ }^{24}$ it was found that the brain accumulation of the NPs was dependent on transferrin level. NPs decorated with a high level of transferrin molecules remain strongly attached to the brain endothelial cells without strong transcytosis, whereas those with less transferrin are able to interact with the transferrin receptors on the luminal side of the BBB and detach at the brain side to reach the brain parenchyma tissues. This study indicates that proper optimization of the avidity

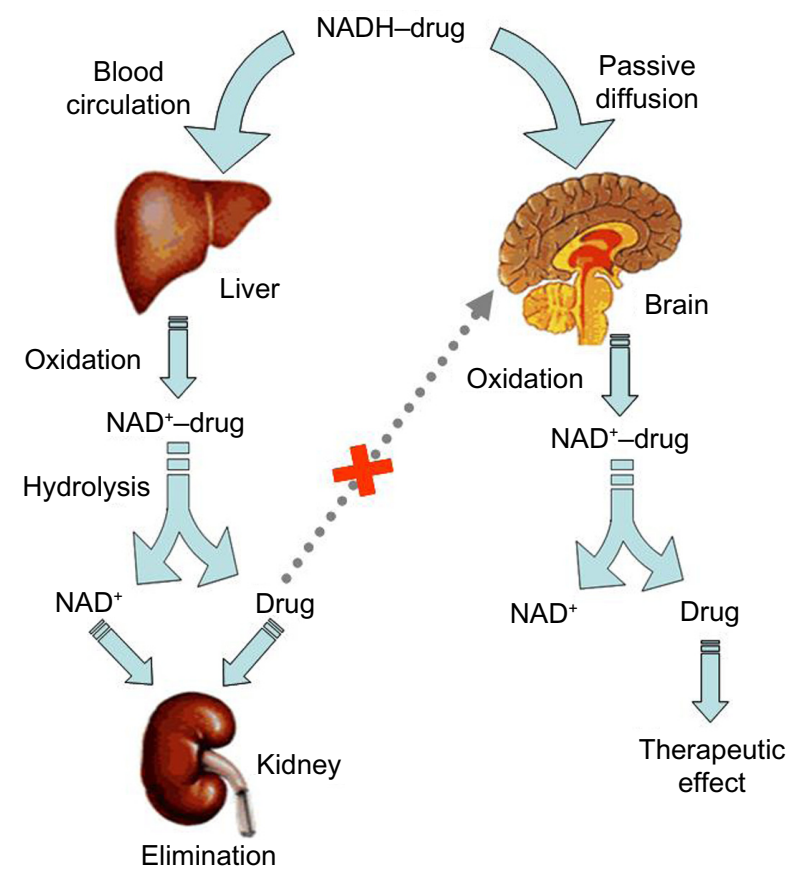

Figure 5 Illustration of I,4-dihydrotrigonelline system.

Abbreviations: $\mathrm{NAD}^{+}$, ionized $\mathrm{NADH} ; \mathrm{NADH}$, nicotinamide adenine dinucleotide. 
is essential to achieve efficient BBB transcytosis using the receptor-mediated mechanism.

\section{Cell-penetrating peptide (CPP)-mediated drug delivery}

Another technique involves the use of CPPs to enhance the CNS delivery. ${ }^{25}$ CPPs contain a sequence of highly basic amino acids which confer a positive charge on the peptide. They interact with the cell surface via a receptor independent mechanism. Furthermore, CPPs can transport the molecules that are tagged to them across the cell membrane, into the cytoplasm and to the nucleus, ${ }^{26,27}$ and this effect is independent of the cell type.

The most frequently studied peptides include HIV-1 (human immunodeficiency virus [HIV] type 1) trans-activating transcriptional activator (TAT) peptide, herpes simplex virus (HSV) type-1 transcription factor (HSV VP-22) peptide, antennapedia, and penetratin. ${ }^{26}$ TAT particularly, is the most studied one. HIV-TAT peptide was discovered in 1988, when researchers observed that TAT protein is able to migrate from the quiescently infected cells that produce this protein to the uninfected cells and initiate viral replication. TAT protein contains the sequence known as protein transduction domain that is responsible for this translocation.

TAT peptide is a relatively small polypeptide of 86 amino acids with a cysteine rich region. ${ }^{28}$ The basic region of TAT peptide consisting of two lysine and six arginine residues is essential for efficient cellular uptake. ${ }^{29}$ It has been observed that TAT peptide permeates the cell membrane in a receptorand transporter-independent mechanism. TAT peptide can permeabilize the cell by forming an inverted micelle, by destabilizing the phospholipid bilayer, by interacting with the negatively charged phospholipids of plasma membrane. ${ }^{30}$

Endocytosis and macropinocytosis are the two primary mechanisms that have been proposed to explain the cellular uptake of TAT peptide. The main benefit of TAT coupling is that, along with efficient delivery of molecules, biological activity of the coupled molecule is preserved. In addition, the size of the molecule being transported is generally not a ratelimiting factor. TAT conjugation was employed to facilitate the delivery of biomacromolecules across the BBB. ${ }^{31}$

\section{Viral vectors}

Viral vectors have become a valuable tool for gene delivery at specific site(s) in the brain. Different strategies are employed to deliver genes to the brain and enhance their distribution. One of the strategies is to inject the viral vectors directly into the cerebral lateral ventricles. By this method, virus will be delivered throughout the CNS. ${ }^{32}$ Another strategy is to inject at multiple sites to cover a large volume. Agents such as mannitol ${ }^{33}$ and heparin ${ }^{34}$ have also been tested to promote the distribution of vectors.

To date, a number of virus classes have been studied as vectors for gene CNS delivery. ${ }^{35}$ These include HSV, ${ }^{36}$ lentivirus, ${ }^{37}$ retrovirus, ${ }^{38}$ recombinant AAV (adeno-associated virus), ${ }^{39}$ simian virus $40,{ }^{40,41}$ and helper-dependent adenovirus. ${ }^{42}$

Moreover, hybrid viral vectors have been constructed to incorporate different viral elements with particular features in order to achieve reproducible and stable gene delivery to the brain. Various types of vectors have been constructed by utilizing the combination of two or more viral elements or gene sources. Examples include HSV/AAV hybrid amplicon vectors, ${ }^{43} \mathrm{HSV} /$ Epstein-Barr virus (EBV) and HSV/EBV/ retrovirus hybrid amplicon vectors ${ }^{44}$ adenovirus/AAV hybrid vectors, ${ }^{45}$ and adenovirus/retrovirus hybrid vectors. ${ }^{46}$

Although viral vectors have generally demonstrated satisfactory efficiency for CNS delivery, they are associated with several problems such as unwanted deleterious immune response, changes in the properties of delivered virus due to endogenous recombination, and mutagenic behavior leading to oncogenesis..$^{35}$ It is highly advisable for the researchers to weigh the risks against the benefits before choosing this class of delivery system.

\section{Colloidal drug carriers}

A colloid is a suspension of microscopically dispersed particles or droplets that typically have a diameter of between 1 and 1,000 nm. ${ }^{47}$ The extensively studied colloidal drug carriers are NPs, micelles, liposomes, emulsions, and dendrimers. Many of these nanomedicines can be effectively transported across various in vitro and in vivo BBB models by endocytosis and/or transcytosis, and have demonstrated early preclinical success for the management of CNS conditions such as brain tumors, HIV encephalopathy, Alzheimer's disease, and acute ischemic stroke. ${ }^{48}$ Particle size, surface affinity, and stability in circulation are the important factors influencing the brain distribution of colloidal particles. ${ }^{49}$

In addition, the brain delivery of colloidal drug carriers can be further enhanced by conjugation to specific targeting agents. Targeted delivery methods independent of the ligandreceptor interactions on the cell surface are currently being used for brain delivery of drugs.

\section{Micelles and microemulsions}

Micelles and microemulsions have demonstrated great promise as intracellular drug delivery systems. 
Theoretically, natural polymer and synthetic polymer materials can be used to prepare micelles and microemulsions. Currently, polymeric micelles, which are the most investigated, usually have a hydrophobic polymer core (eg, poly(propylene glycol), poly(D,L-lactide), and poly(caprolactone)) and a shell of hydrophilic polymer blocks (eg, poly(ethylene glycol) [PEG]). The self-assembly method is the most used preparation for polymeric micelles. Pluronic block copolymer micelles can inhibit drug efflux transporters and enhance drug transport to the CNS. ${ }^{50}$ Furthermore, pluronics inhibit the P-glycoprotein efflux transporters widely expressed on the $\mathrm{BBB}^{51}$ and do not demonstrate any toxicity to the BBB.

Some newer micelle systems directly conjugate the drug molecule and targeting moiety to the amphiphilic portion. ${ }^{52,53}$ For instance, transferrin-modified cyclo-(Arg-Gly-Asp-dPhe-Lys)-paclitaxel conjugate-loaded micelle was studied by Zhang et al. ${ }^{54}$ They demonstrated enhanced uptake by the brain microvascular endothelial cells in vitro as well as prolonged drug retention in glioma tumor in vivo. No significant toxicity was observed. The small size and versatility of micelles clearly make this class of delivery system a promising choice for brain delivery.

The microemulsion concept was introduced as early as the 1940 s by Hoar and Schulman ${ }^{55}$ who generated a clear single-phase solution by titrating a milky emulsion with hexanol. A microemulsion is defined as a system of water, oil, and amphiphile, which is a single optically isotropic and thermodynamically stable liquid solution. Surfactant molecules that stabilize microemulsions are usually the same as those that form micelles. With high loading capacity and good penetration ability, this nanoscale system is appealing to pharmaceutical scientists. In addition, microemulsion can deliver drug molecules via a wide range of administration routes such as oral, nasal, parenteral, pulmonary, and ocular delivery. ${ }^{56}$ It is noticeable from the literature that there has recently been a significant increase in the number of scientific articles describing the use of block copolymer microemulsion for CNS delivery. Mechanistically, the dynamics associated with such systems have much in common with the conventional microemulsion stabilized by non-polymeric surfactants.

\section{Liposomes}

Liposomes are lipid vesicles consisting of either one or more phospholipid bilayers. They consist of an aqueous core for encapsulation of hydrophilic drugs, while amphiphilic and lipophilic drugs can be solubilized within the phospholipid bilayer. Conventional liposomes are characterized by lower plasma circulation times as a result of elimination by the reticuloendothelial system. Extended circulation time can be achieved by decreasing the particle size $(<100 \mathrm{~nm})$ or by modification of the liposome surface with PEG (ie, stealth liposomes).

Surface-modification methods have also been studied to increase the brain distribution for loaded liposomes. ${ }^{57-59}$

Transferrin receptor is a targeting ligand which is overexpressed on the surface of many tumor cells. ${ }^{60}$ Hatakeyama et $\mathrm{al}^{61}$ found that transferrin-modified liposomes less than $80 \mathrm{~nm}$ have the ability to target the brain. Glucose is an essential nutritional substance for brain function sustenance, which cannot be synthesized by the brain. Its transport primarily depends on the glucose transporters on the brain capillary endothelial cells. Xie et $\mathrm{al}^{62}$ showed that the glucosemodified liposomes GLU1000-LIP exhibit a strong brain delivery capacity.

TAT peptide is another modified targeting ligand which can be used to enhance the CNS delivery. ${ }^{63}$ The TAT conjugation ensured that BBB absorption was mediated by transport mechanisms other than transcytosis, in addition to having the ability to bypass the efflux mechanism of various transport proteins in the BBB. ${ }^{64}$

However, there has always been a concern about delivering highly active agents across the BBB to healthy, noncancerous tissues in the brain in a nonspecific manner, especially for the chemotherapeutics. Most recently, Gao et al developed a dual-targeting liposomal formulation to tackle this issue. ${ }^{65,66}$ Liposomes encapsulating doxorubicin were conjugated with both transferrin and folate, with one to improve $\mathrm{BBB}$ transcytosis and the other molecule to enhance the specificity for the cancer cells in the brain. The dual-targeting doxorubicin liposomes were found capable of improving the therapeutic efficacy of brain glioma and were less toxic than the free-drug solution. This study demonstrates the key strength of liposomes (ie, the ease of surface modification).

\section{NPs (nanospheres and nanocapsules)}

NPs can be divided into two classes: nanocapsules (core-shell structure) and nanospheres (matrix structure). Currently, NPs are gaining wide interest as carriers for the CNS delivery of various therapeutic agents including protease inhibitors. ${ }^{67}$ This is because NPs offer more stability to the encapsulated drug in biological fluids and against enzymatic metabolism as compared with other colloidal systems such as liposomes or micelles. ${ }^{68}$ Drugs that have been successfully reported in brain delivery using NPs include loperamide, tubocurarine, 
and doxorubicin. ${ }^{69}$ By encapsulating the drug within NPs, efflux of the drug can be minimized, thus facilitating its CNS entry.

Several general categories of NPs have been used in drug delivery. ${ }^{70}$ Polymeric NPs consist of non-soluble polymers that are often biodegradable. As a result they can release the entrapped drugs as the polymer degrades or by passive diffusion of the drug from the polymeric core. Among a wide range of polymers, polylactide homopolymers (polylactic acid) and poly(lactide-co-glycolide) (PLGA) are two well known classes of polymers approved by the Food and Drug Administration (FDA) for human use. Development of NPs formulated from polylactic acid and PLGA offers several advantages for CNS delivery of therapeutic agents. These polymers are biodegradable, biocompatible, and their NPs do not induce any inflammatory response after injection. ${ }^{67}$ In addition, their degradation products (ie, glycolic acid and lactic acid) are eventually converted to carbon dioxide and water through the Kreb's cycle and finally eliminated. ${ }^{68}$ Furthermore, a wide variety of hydrophilic and hydrophobic drugs can be entrapped within their matrix, along with the ability to release the entrapped drug in a sustained manner for several weeks. ${ }^{71}$ However, although these NPs can permeate the $\mathrm{BBB}$, their transport efficiency is not high enough to result in therapeutic effects in the CNS.

Therefore, functionalizing the NPs by surface modification and conjugation with transporters of the $\mathrm{BBB}$ has been proposed to enhance their transport efficiency into the brain. ${ }^{49,72,73}$

Surface modification of NPs includes surfactant modification and antibody modification. ${ }^{52}$ The antibody modification approach is to modify the surface of the NPs with an antibody that is particularly specific for the brain (eg, the OX26 antibody and the transferrin receptor). With receptor-mediated endocytosis, antibody-conjugated NPs are most promising tools for CNS targeting because of their capacity for specific binding. For instance, antibodies targeted to transferrin and insulin receptors can act as transporters across the BBB and deposit the drug molecules via receptor-mediated endocytosis. From reported researches, chemotherapeutic drugs like methotrexate and proteins like basic fibroblast growth factor, nerve growth factor, and brain-derived neurotrophic factor are successfully transported into the brain upon conjugation with the transferrin receptor antibody. ${ }^{53,74}$

Many bio-adhesive surfactants can be used in the surface modification approach to enhance adhesion and adsorption by intestinal cells, while masking efflux mechanisms. ${ }^{47,73,75}$
Polysorbate 80 was one of the most studied surfactants used in the surface modification of NPs. Polysorbate 80 surfacemodified doxorubicin-loaded and gemcitabine-loaded poly(butylcyanoacrylate) NPs show enhanced brain specificity and efficacy compared with unmodified NPs. ${ }^{76-78}$ Another surfactant reported to have the ability to enhance brain permeability is poloxamer 188 (F68) which has been found to increase the delivery of drug-loaded polybutylcyanoacrylate and PLGA NPs to the brain in rats. ${ }^{20,79} \mathrm{~A}$ further study conducted by Kulkarni et $\mathrm{al}^{73}$ demonstrated more effective delivery of F68-modified PLGA NPs than poloxamer 407 (F127) and polysorbate 80-modified NPs into the brain.

The plausible mechanism behind enhanced brain permeation by these surfactants is that they inhibit the efflux action of P-glycoprotein and solubilize the cell membrane lipids of brain endothelial cells for entry. ${ }^{73}$ Also, polysorbate 80 and F68 surface-modified NPs adsorb apolipoprotein E, apolipoprotein B, or both, mimic low-density lipoproteins, and enter the brain via receptor-mediated endocytosis. ${ }^{80}$ Thus, it can be understood that surface modification will essentially influence the pattern of NP uptake by cells.

Many transporters found in the BBB have been investigated for brain delivery, such as vascular endothelial growth factor, epidermal growth factor, insulin-like growth factor, insulin, albumin, transferrin, lactoferrin, and angiopep-2. For example, the conjugation of an NP with lactoferrin, resulting in greater BBB absorption of lactoferrin-conjugated NPs compared with unconjugated NPs, due to the presence of the lactoferrin receptor on the surface of the BBB. ${ }^{75}$ The tetanus toxin $\mathrm{C}$ fragment (TTC) is efficiently retrogradely transported in neurons and binds to neurons with high specificity and affinity. Townsend et al found that TTC-conjugated NPs have a strong affinity for neurons in the periphery, ${ }^{24}$ which could be used as an efficient drug delivery vehicle targeted to the CNS via retrograde transport. Shilo et al ${ }^{65}$ prepared insulin-targeted gold NPs and injected them into the tail vein of male BALB/c mice to investigate the receptor-mediated endocytosis process. From the results, the amount of insulintargeted gold NPs found in mice brains 2 hours after injection was over five times greater than that of the control (untargeted gold NPs).

NP transport across the BBB may be diminished due to intracellular accumulation at the endothelial cells as large aggregates. This issue can be addressed using the "shuttlemediated" transport strategy. Guarnieri et al ${ }^{53,81}$ recently demonstrated that by conjugating NPs with a viral fusion peptide (gH625) derived from the glycoprotein $\mathrm{gH}$ of HSV, the aforementioned tendency of forming NP aggregates 
within the cells is decreased, and improved BBB transport is subsequently noticed. This is a noteworthy finding as most researchers tend to focus on increasing the NP binding on the endothelial cell surface, with less attention paid to what occurs after the binding. The NPs may simply get stuck on the cell surface or inside the cells, without actual improvement in the BBB passage for the desired brain targeting.

\section{Solid lipid NPs (SLNs)}

SLNs were developed at the beginning of the 1990s as alternative colloidal carriers to emulsions, liposomes, and polymeric NPs. An SLN is typically spherical with an average diameter of between 10 and $1,000 \mathrm{~nm}$. SLNs possess a solid lipid core matrix that is stabilized by surfactants. SLNs have been used as brain targeted delivery systems for many therapeutics, such as doxorubicin, ${ }^{82}$ docetaxel, ${ }^{83}$ quercetin, ${ }^{84}$ atazanavir, ${ }^{85}$ and quinine. ${ }^{86}$

Nowadays, PEGylated SLNs have been widely investigated for brain drug delivery. ${ }^{87,88}$ SLNs and PEGylated SLNs are readily taken up by the brain tissues because of their lipidic nature. The biocompatible and biodegradable nature of SLNs makes them normally less toxic when compared with polymeric NPs. Supplemented with their small size, which prolongs the circulation time, feasibility for large scale production and absence of burst effect makes them promising candidates as CNS delivery carriers. ${ }^{89}$

\section{Dendrimers}

Dendrimer, from the Greek word (dendron) for tree, refers to a synthetic, three-dimensional molecule with branching parts. Dendrimers are formed using a nanoscale, multistep fabrication process. Dendrimers are highly versatile nanocarriers that show good potential in brain delivery. ${ }^{90}$ The surfaces of dendrimers can be easily functionalized due to the availability of multiple reactive functional groups.

Huang et $a 1^{91}$ observed a significant increase in the brain uptake of DNA (deoxyribonucleic acid) complexed with transferrin-conjugated polyamidoamine dendrimers. Transferrin was selected as the targeting moiety since brain capillaries are known to express a high level of transferrin receptors. In another study, mannosylated polyamidoamine dendrimers loading lamivudine were evaluated for their in vitro antiretroviral activity in HIV-infected MT2 cells. It was found that encapsulation of lamivudine within dendrimers enhanced the antiretroviral activity as a result of a 21-fold increase in drug uptake when compared with the drug in solution. Consequently, the viral p24 level was reduced 2.6-fold when compared with the free drug. ${ }^{92}$
The key limitations of dendrimer-based drug delivery platforms are the variability of their drug-release mechanisms and the short-term of their release kinetics. Drugs encapsulated within dendrimers have a tendency to be released quickly, unloading their payload prematurely before the delivery platforms even reach the targets. ${ }^{93}$

\section{Other colloidal carriers}

In addition to the colloidal carriers mentioned above, there are some colloidal carriers that can be applied as CNS delivery platforms, such as polyethyleneimine (PEI) derivatives and single-walled carbon nanotubes. ${ }^{94}$

PEI is an organic polymeric molecule with a high cationiccharge-density potential based on the presence of multiple amino groups within its backbone. Carbon nanotubes are a new allotropic form of carbon which consists of seamless graphene sheets rolled concentrically to form capped cylinders mostly composed of carbon hexagons and highly strained regions at the tips, where carbon pentagons are the predominant shape. In some experiments in vitro, PEI derivatives and carbon nanotubes have shown high efficiency for gene transfer. Although their cellular uptake mechanism in the CNS is unclear, ${ }^{95}$ these novel colloidal carriers might potentially serve as alternative delivery systems for CNS diseases in future. ${ }^{96,97}$

\section{Invasive techniques}

Generally, only a few peptides and nutrients can cross the BBB to achieve effective concentration within the brain tissue following intravenous or oral administration. ${ }^{98,99}$

To deliver sufficient amounts of highly potent drugs (eg, anticancer drugs and neurotrophic factors) to the CNS by systemic routes, it is inevitable these drugs will distribute in other tissues to cause serious toxic side effects. Sometimes, it is necessary to disrupt the BBB or administer these drugs directly into the brain tissue. ${ }^{100}$

\section{Intracerebral implants}

Intracerebral implantation of therapeutic agents containing biodegradable polymeric matrix or reservoir is a highly traumatic drug-delivery strategy, which has been utilized in a number of clinical trials. Table 2 shows the advantages and disadvantages of polymer-controlled implant for CNS delivery.

In 1996, the FDA approved a BCNU (bischloroethylnitrosourea) (carmustine)-contained polyanhydride polymer wafer for recurrent high-grade gliomas. ${ }^{101}$ With a combination of diffusion and hydrolytic polymer degradation, this matrix maintains a sustained drug release for about 2 months. 
Table 2 Advantages and disadvantages of polymeric-controlled implant for central nervous system delivery

\begin{tabular}{ll}
\hline Advantages & Disadvantages \\
\hline Sustained drug release & Poor drug penetration \\
Define release kinetics & Drug dosage limited by \\
Tunable release properties & implant size \\
Low invasiveness & \\
Low peak drug release limits tissue damage & \\
Biocompatible & \\
Localized delivery & \\
\hline
\end{tabular}

Intracerebral implantation has also been tried in some chemotherapeutics. ${ }^{102-104}$ However, the increased risk of trauma and poor drug penetration beyond the resection cavity limited the local delivery strategy.

\section{Intraventricular/intrathecal/ interstitial delivery}

The most direct way of circumventing the BBB is to deliver drugs directly to the intraventricular, intracavitary, or interstitial system. With intermittent bolus injections, these local delivery strategies can theoretically yield high drug concentrations in the CNS with minimal systemic exposure and toxicity.

By administering anticancer drugs locally to an intracranial target, sustained intracranial drug concentrations can be achieved. ${ }^{105,106}$

These delivery strategies are considered the most appealing means for the treatment of primary brain tumors, because they provide the most direct route to overcome the barriers to tumor drug delivery. Some drugs, such as nitrosourea and methotrexate, have been used in various clinical trials with promising results. However, this strategy has certain disadvantages, including CNS infection, catheter obstruction, and inadequate drug distribution. ${ }^{107}$

\section{Biological tissue delivery}

Another strategy to achieve interstitial drug delivery involves releasing drugs from biological tissues. The simplest approach to this technique is to implant into the brain a tissue that naturally secretes a desired therapeutic agent. This approach has been most extensively applied to the treatment of Parkinson's disease. ${ }^{108}$ However, transplanted tissue cannot survive due to a lack of neovascular innervation. The survival of foreign tissue grafts may be improved by advancements in techniques for culturing distinct cell types. Co-grafted cells engineered to release neurotropic factors, with cells engineered to release therapeutic proteins, may enhance the survival and development of foreign tissue. Recently, enhanced vascularization and microvascular permeability in cell-suspension embryonic neural grafts relative to solid grafts has been demonstrated. ${ }^{109}$

\section{BBB disruption (BBBD) strategies}

As an effective invasive technique, BBBD strategies are elaborated as an independent part in parallel with the invasive technique section. Different techniques for BBBD have been investigated, and encouraging results have been achieved.

\section{Convection-enhanced delivery (CED)}

CED is a delivery technique to administer therapeutic agents directly into targeted brain parenchyma or tissue. As shown in Figure 6, CED involves one or more catheters stereotactically placed through cranial burr holes into the brain. Therapeutic agents are subsequently administered by microinfusion pump. ${ }^{104,110}$

Compared with traditional delivery methods, CED has shown its unique characteristics for CNS delivery. ${ }^{111}$ Without molecular weight limitation, CED can provide effective drug concentration in the region of structure into which the catheter is placed (Table 3). Furthermore, CED within the defined infusion measurements does not produce cerebral edema or measurable increases in intracranial pressure. ${ }^{112}$

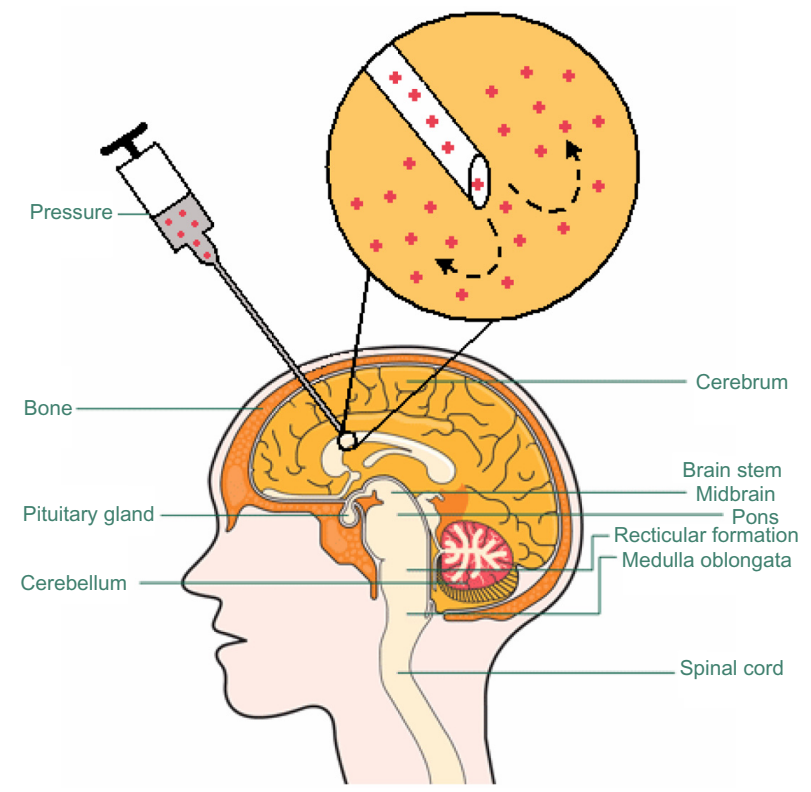

Figure 6 Illustration of convection-enhanced delivery. Using a microinfusion pump, molecules are infused through a cannula inserted into the target. Continuous positive pressure, driven by the micro-infusion pump, is maintained at the lip of the cannula. This pressure gradient provides the convective flow to push the molecules further away from the cannula lip. 
Table 3 Advantages and disadvantages of convection-enhanced drug delivery

\begin{tabular}{ll}
\hline Advantages & Disadvantages \\
\hline High concentration in brain & Invasive \\
CNS-targeted effects & Long infusion times \\
Lower systemic side effects & Unpredictable drug distribution \\
Large drug distribution volume & Potential high intracranial pressures \\
Flexible therapy protocol & Local toxicity \\
Consistent drug concentration & \\
\hline
\end{tabular}

Abbreviation: CNS, central nervous system.

\section{Osmotic BBBD strategy}

Transient osmotic disruption of the BBB, BCSFB, and bloodtumor barriers can be realized by intra-arterial infusion of a hyperosmotic agent. ${ }^{113}$ Hyperosmolar mannitol solution is the most frequently used agent for achieving BBBD, ${ }^{114,115}$ which can increase the BBB permeability by inducing the shrinkage of cerebrovascular endothelial cells, thus producing a disruption of inter-endothelial TJs for several hours. ${ }^{116}$

Besides mannitol, hyperosmolar solutions of arabinose, lactamide, saline, urea, and radiographic contrast agents can be used to transiently breach the BBB. Since its initial description by Rapoport in 1972, the strategy has been used in preclinical and even clinical studies. ${ }^{117,118}$ An unfavorable toxic/therapeutic ratio is often observed with hyperosmotic BBBD. So this technique needs to be carefully used to avoid unwanted neurotoxicity. ${ }^{119}$

\section{Biochemical BBBD strategy}

Some vasoactive compounds, including leukotrienes, bradykinin, and histamine, appear to selectively increase the permeability in abnormal brain capillaries. ${ }^{120}$ Normal brain capillaries resist the effects of these compounds through an "enzymatic barrier" that may inactivate vasoactive agents.
In contrast, this enzymatic barrier is lost in certain diseased states, allowing vasoactive compounds to selectively increase permeability in abnormal capillaries. Clinically, intracarotid infusion of leukotrienes, bradykinin, and other vasoactive agents can increase drug delivery to diseased tissue. Unlike osmotic disruption methods, biochemical BBBD is a less invasive and possibly a more reliable technique for BBBD because it mainly affects the diseased vasculature.

\section{Ultrasound (US)-mediated BBBD strategy}

US consists of pressure waves having frequencies of $20 \mathrm{kHz}$ or greater. Like optical and audio waves, ultrasonic waves can be focused, reflected, and refracted through a medium. ${ }^{121-123}$

A major limitation in the utilization of US for BBBD has been the poor penetration of US through the skull, and for several decades it was believed that the skull bone had to be removed to perform US treatments in the brain. ${ }^{124}$ However, experimental and theoretical studies have shown that it is feasible to achieve focal, trans-skull focused US (FUS) exposure of brain tissue by using large surface area phased arrays. ${ }^{125,126}$ Recently developed image-guided (eg, magnetic resonance imaging [MRI]-guided) FUS clinical systems have made it possible to deliver therapeutics to the targeted regions in the brain through the intact skull, and both animal studies and clinical trials have shown encouraging results. ${ }^{127}$

As shown in Figure 7, ultrasonic microbubbles combined with FUS can be used as drug carriers for targeted delivery. ${ }^{121,123}$ Preformed microbubbles with narrow size distribution have been used to achieve a repeatable cavitation environment with controlled source of cavitation nuclei.

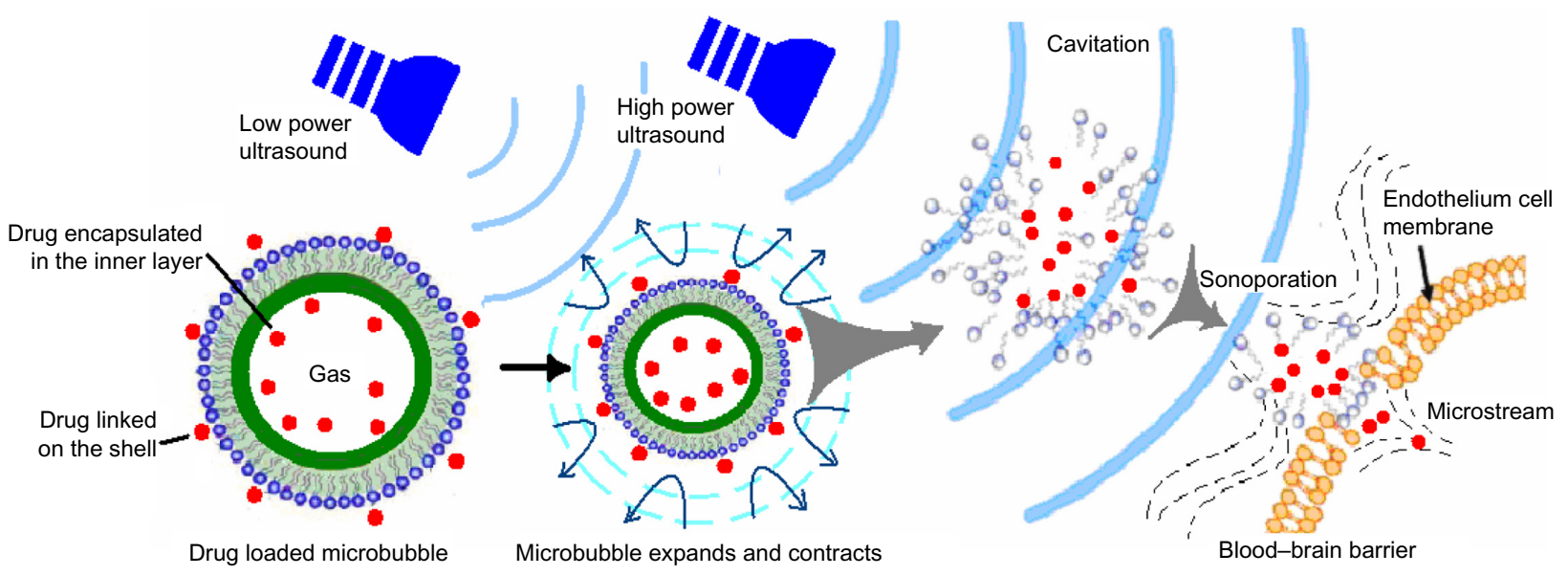

Figure 7 Illustration of ultrasonic microbubbles for drug targeted delivery. 
Cavitation is defined as the oscillation of bubbles in an acoustic field. Cavitation can produce strong stresses on cells to achieve various "bioeffects." For instance, it may increase drug interaction by upregulating pathways of various types of stress response, or result in physical shearing of the cell membrane to promote direct passage of therapeutics into the cytosol. With ultrasonic microbubbles in blood vessels, the acoustic energy required by the cavitation will be greatly reduced. ${ }^{127}$ This technique makes the procedure more practical for application through the intact skull, since the risks of overheating the skull would be significantly reduced. Furthermore, with the use of these agents, the interaction of the US with the endothelial cells can be limited, so the chance of damage to other brain structures can be minimized.

\section{Alternative routes for CNS drug delivery Olfactory and trigeminal pathways to the CNS}

The intranasal route is an alternative route bypassing the cardiovascular system. As shown in Figure 8, the neural pathways connecting the nasal mucosa and the brain provide potential routes for noninvasive drug delivery to the CNS. ${ }^{128-130}$ The nose-to-brain pathway enables quick delivery of the therapeutic agents to the CNS within minutes. Drugs with lower molecular weight and higher lipophilicity generally favor rapid intranasal uptake into the CNS. The physicochemical properties of small molecules such as size and lipophilicity have been reported to affect the efficiency of CNS delivery following intranasal administration. ${ }^{131}$

Lipid-based NPs have been studied for intranasal drug delivery. Eskandari et al ${ }^{132}$ developed nanostructured lipid carriers encapsulating valproic acid and compared the neuroprotective effects and drug accumulation in brain of this nanoformulation in a rat electroshock model, administered via different routes (intranasal versus intraperitoneal). They demonstrated that the nanoformulation provides significant protective effects against the electroshocks regardless of the route of administration. More interestingly, it was found that intranasal administration actually results in a much higher brain to plasma drug concentration ratio than the intraperitoneal administration. This finding offers concrete evidence showing the potential advantage of intranasal delivery over other systemic routes of administration.

There are a number of limitations for the use of intranasal delivery. For example, there are upper limits of the concentrations that can be achieved in different regions of the brain and spinal cord. The efficiency of drug delivery tends to diminish with increasing molecular weight of the drug. In addition, the mucosal irritation caused by nasal pathology should be avoided. ${ }^{34}$

\section{lontophoretic delivery}

Recently, there has been an increased interest in using the iontophoretic technique for CNS drug delivery. Iontophoresis is a method to deliver ionized molecules across the BBB by using an externally applied electric current. ${ }^{133}$

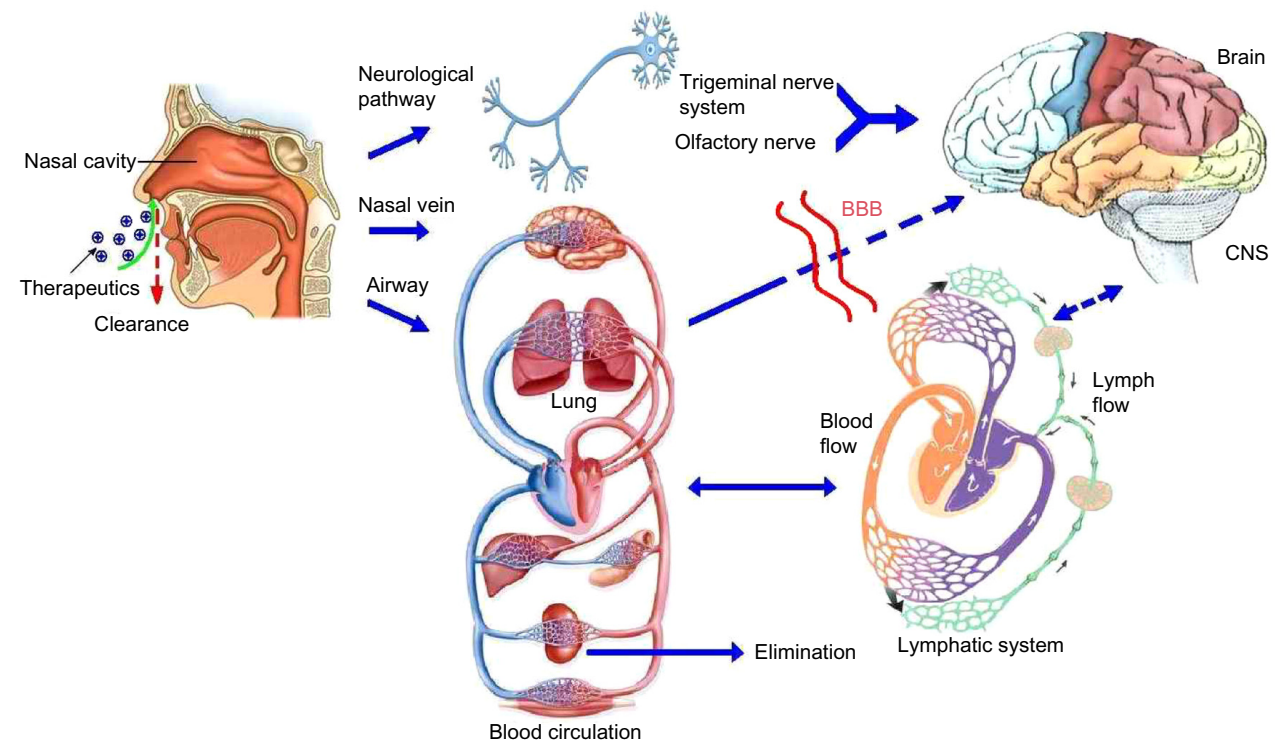

Figure 8 Olfactory and trigeminal pathways to the CNS.

Abbreviations: BBB, blood-brain barrier; CNS, central nervous system. 
Some noninvasive iontophoretic devices using the olfactory pathway have been designed for drug delivery to the CNS. Besides the noninvasive methods, invasive methods and devices have also been presented for enhanced delivery of macromolecule agents to the brain. With programmable transport, these devices for iontophoresis allow for enhanced drug delivery into the brain under controlled manipulation.

\section{Conclusion}

With the rapid development of modern society and the continued deterioration of the environment, brain diseases such as neurodegenerative disease (eg, Alzheimer's disease and Parkinson's disease), stroke, neuroinflammation, and neuro-oncology have become distressful and even devastating issues for human beings.

Drug delivery across the physiological barriers of the brain is the bottleneck for the treatment of CNS disorders and brain tumors. The delivery of most drugs to the CNS is limited by the anatomical structure at the BBB and BCSFB. It is therefore critical to search for alternative CNS delivery routes to achieve effective drug concentrations in the brain. In fact, it has been recognized that there is already an ongoing shift from the traditional CNS therapy toward CNS targeting therapies.

In this article, some promising strategies for efficient CNS delivery were reviewed. Although most of these approaches still remain in the experimental stage, continuing effort in obtaining improved understanding of the mechanisms involved and developing new CNS delivery approaches will facilitate faster translation and widespread adoption of these techniques in clinical applications. While current studies have made remarkable progress, it is worth noting that clinical translation of BBB opening technique is still associated with several concerns.

The first concern is the reproducibility and feasibility of these BBB opening strategies. Although some encouraging results were obtained in animal experiments, the complexity of the agents or settings used in various strategies would limit their future applications. For example, surface modified nanoscale particles have their advantages in BBB opening strategies, but most of these nanoscale particles are self-made agents. Strictly speaking, the data from experiments using the same strategy are not comparable because the components in these agents are different. Even for those agents composed of the same components, the various characteristics resulting from their different preparations or surface modifications still affect the accuracy of the results.
Another concern is the safety of repeated BBB opening treatment over weeks and even longer for chemotherapy (such as Herceptin ${ }^{\circledR}$ [Genentech Inc., South San Francisco, CA, USA] or doxorubicin) recipients. Many medical imaging and intervention methods such as FUS, MRI, and nuclear magnetic resonance have been explored in facilitating brain drug delivery because these methods have irreplaceable advantageous characteristics in monitoring the drug distribution and concentration in the brain. More combinations of noninvasive real-time imaging tools with drug-loaded nanoscale particles may provide more extensive data to understand this aspect.

Finally, while exciting results have been obtained and manipulative procedures have been established in animals, it should be noted that these BBB opening strategies have only been proven to be feasible in rodent experiments. The physiological structure of the BBB is not the same in primates. Thus, the results obtained from rodents may not be applicable to humans, and investigations in primates with rigorous experimental designs and clinical trials are required before these techniques can be applied for the treatment of human brain diseases. After properly addressing these issues, nanocarriers combined with medical imaging and BBBD strategies may pave the way to successfully deal with a large range of CNS diseases.

To conclude, targeted CNS therapeutics is an ever expanding and challenging but promising field. Design and development of effective targeted CNS therapeutics require thorough understanding of the physiochemical properties of the drugs, biopharmaceutical and pharmacokinetic action of the carriers, as well as the biological parameters of the CNS. Further insights into the molecular mechanisms involved in BBB and BCSFB regulation will provide additional molecular cues for more selective and efficient targeting of the brain barriers in CNS diseases.

\section{Acknowledgments}

This research was supported by the National Natural Science Funds (Grant No 81272160, 81360195, 81301982, $81371558,81302726,81101570,81000526$, and 81271584), Zhejiang Provincial Natural Science Foundation (Grant No LY12H30003, LY12H18001, LQ12H30001, and LY12H03001), Zhejiang Provincial Foundation for Health Department (Grant No 2012KYB126 and 2012KYA134), Zhejiang Provincial Project of Key Scientific Group (Grant No 2012R10042-06), Medicine Grant from Wenzhou Bureau of Science and Technology (Grant No H20110008 and Y20110034), and Major Scientific Project of Guangdong Province (Grant No 2012A080201010). 


\section{Disclosure}

The authors report no conflict of interests in this work.

\section{References}

1. Begley DJ. Delivery of therapeutic agents to the central nervous system: the problems and the possibilities. Pharmacol Ther. 2004;104:29-45.

2. Chen Y, Dalwadi G, Benson HA. Drug delivery across the blood-brain barrier. Curr Drug Deliv. 2004;1:361-376.

3. Madrid Y, Langer LF, Brem H, et al. New directions in the delivery of drugs and other substances to the central nervous system. $A d v$ Pharmacol. 1991;22:299-324.

4. Dwibhashyam VS, Nagappa AN. Strategies for enhanced drug delivery to the central nervous system. Indian J Pharm Sci. 2008;70:145-153.

5. Vykhodtseva N, McDannold N, Hynynen K. Progress and problems in the application of focused ultrasound for blood-brain barrier disruption. Ultrasonics. 2008;48:279-296.

6. Sai Y, Kajita M, Tamai I, et al. Adsorptive-mediated endocytosis of a basic peptide in enterocyte-like Caco-2 cells. Am J Physiol. 1998;275: G514-G520.

7. Tamai I, Tsuji A. Transporter-mediated permeation of drugs across the blood-brain barrier. J Pharm Sci. 2000;89:1371-1388.

8. Tsuji A. Small molecular drug transfer across the blood-brain barrier via carrier-mediated transport systems. NeuroRx. 2005;2:54-62.

9. Schinkel AH. The roles of P-glycoprotein and MRP1 in the bloodbrain and blood-cerebrospinal fluid barriers. Adv Exp Med Biol. 2001;500:365-372.

10. Thiebaut F, Tsuruo T, Hamada H, et al. Immunohistochemical localization in normal tissues of different epitopes in the multidrug transport protein P170: evidence for localization in brain capillaries and crossreactivity of one antibody with a muscle protein. J Histochem Cytochem. 1989;37:159-164.

11. Banks WA, Kastin AJ, Ehrensing CA. Endogenous peptide TyrPro-Trp-Gly-NH2 (Tyr-W-MIF-1) is transported from the brain to the blood by peptide transport system-1. J Neurosci Res. 1993;35: 690-695.

12. Albert A. Chemical aspects of selective toxicity. Nature. 1958;182: 421-422.

13. Pardridge WM. Recent advances in blood-brain barrier transport. Annu Rev Pharmacol Toxicol. 1988;28:25-39.

14. Bodor N, Buchwald P. Recent advances in the brain targeting of neuropharmaceuticals by chemical delivery systems. Adv Drug Deliv Rev. 1999;36:229-254.

15. Brewster ME, Anderson WR, Webb AI, et al. Evaluation of a brain-targeting zidovudine chemical delivery system in dogs. Antimicrob Agents Chemother. 1997;41:122-128.

16. Brewster ME, Raghavan K, Pop E, et al. Enhanced delivery of ganciclovir to the brain through the use of redox targeting. Antimicrob Agents Chemother. 1994;38:817-823.

17. Wu WM, Pop E, Shek E, et al. Brain and CSF specific chemical delivery systems for beta-lactam antibiotics. Study of two dihydropyridine derivatives of benzylpenicillin in rabbits and dogs. Drug Des Deliv. 1990;7:33-43.

18. Sikic BI, Fisher GA, Lum BL, et al. Modulation and prevention of multidrug resistance by inhibitors of P-glycoprotein. Cancer Chemother Pharmacol. 1997;40 Suppl:S13-S19.

19. Bodor N, Buchwald P. Barriers to remember: brain-targeting chemical delivery systems and Alzheimer's disease. Drug Discov Today. 2002;7:766-774.

20. Petri B, Bootz A, Khalansky A, et al. Chemotherapy of brain tumour using doxorubicin bound to surfactant-coated poly(butyl cyanoacrylate) nanoparticles: revisiting the role of surfactants. $J$ Control Release. 2007;117:51-58.

21. Bodor N, Prokai L, Wu WM, et al. A strategy for delivering peptides into the central nervous system by sequential metabolism. Science. 1992;257:1698-1700.
22. Kang YS, Bickel U, Pardridge WM. Pharmacokinetics and saturable blood-brain barrier transport of biotin bound to a conjugate of avidin and a monoclonal antibody to the transferrin receptor. Drug Metab Dispos. 1994;22:99-105.

23. Wiley DT, Webster P, Gale A, Davis ME. Transcytosis and brain uptake of transferrin-containing nanoparticles by tuning avidity to transferrin receptor. Proc Natl Acad Sci USA. 2013;110:8662-8667.

24. Townsend SA, Evrony GD, Gu FX, et al. Tetanus toxin C fragmentconjugated nanoparticles for targeted drug delivery to neurons. Biomaterials. 2007;28:5176-5184

25. Pardridge WM, Boado RJ, Kang YS. Vector-mediated delivery of a polyamide ("peptide") nucleic acid analogue through the blood-brain barrier in vivo. Proc Natl Acad Sci U S A. 1995;92:5592-5596.

26. Huwyler J, Wu D, Pardridge WM. Brain drug delivery of small molecules using immunoliposomes. Proc Natl Acad Sci U S A. 1996;93: 14164-14169.

27. Temsamani J, Vidal P. The use of cell-penetrating peptides for drug delivery. Drug Discov Today. 2004;9:1012-1019.

28. Zheng L, Yang YD, Lu GC, et al. Extracellular HIV Tat and Tat cysteine rich peptide increase CCR5 expression in monocytes. J Zhejiang Univ Sci B. 2005;6:668-672.

29. Vives E, Brodin P, Lebleu B. A truncated HIV-1 Tat protein basic domain rapidly translocates through the plasma membrane and accumulates in the cell nucleus. J Biol Chem. 1997;272: 16010-16017.

30. Derossi D, Calvet S, Trembleau A, et al. Cell internalization of the third helix of the Antennapedia homeodomain is receptor-independent. J Biol Chem. 1996;271:18188-18193.

31. Schwarze SR, Ho A, Vocero-Akbani A, Dowdy SF. In vivo protein transduction: delivery of a biologically active protein into the mouse. Science. 1999;285:1569-1572.

32. Kravcik S, Gallicano K, Roth V, et al. Cerebrospinal fluid HIV RNA and drug levels with combination ritonavir and saquinavir. J Acquir Immune Defic Syndr. 1999;21:371-375.

33. Lindgren M, Hallbrink M, Prochiantz A, et al. Cell-penetrating peptides. Trends Pharmacol Sci. 2000;21:99-103.

34. Misra A, Ganesh S, Shahiwala A, et al. Drug delivery to the central nervous system: a review. J Pharm Pharm Sci. 2003;6:252-273.

35. Kumar A, Singh TD, Singh SK, et al. Methods, potentials, and limitations of gene delivery to regenerate central nervous system cells. Biologics. 2009;3:245-256.

36. Wolfe D, Goins WF, Yamada M, et al. Engineering herpes simplex virus vectors for CNS applications. Exp Neurol. 1999;159: $34-46$.

37. Geraerts M, Eggermont K, Hernandez-Acosta P, et al. Lentiviral vectors mediate efficient and stable gene transfer in adult neural stem cells in vivo. Hum Gene Ther. 2006;17:635-650.

38. Cepko CL, Ryder E, Austin C, et al. Lineage analysis using retroviral vectors. Methods. 1998;14:393-406.

39. Mori S, Wang L, Takeuchi T, et al. Two novel adeno-associated viruses from cynomolgus monkey: pseudotyping characterization of capsid protein. Virology. 2004;330:375-383.

40. Louboutin JP, Reyes BA, Agrawal L, et al. Strategies for CNS-directed gene delivery: in vivo gene transfer to the brain using SV40-derived vectors. Gene Ther. 2007;14:939-949.

41. Strayer DS, Agrawal L, Cordelier P, et al. Long-term gene expression in dividing and nondividing cells using SV40-derived vectors. Mol Biotechnol. 2006;34:257-270.

42. Cregan SP, MacLaurin J, Gendron TF, et al. Helper-dependent adenovirus vectors: their use as a gene delivery system to neurons. Gene Ther. 2000;7:1200-1209.

43. Costantini LC, Jacoby DR, Wang S, et al. Gene transfer to the nigrostriatal system by hybrid herpes simplex virus/adeno-associated virus amplicon vectors. Hum Gene Ther. 1999;10:2481-2494.

44. Oehmig A, Fraefel C, Breakefield XO, et al. Herpes simplex virus type 1 amplicons and their hybrid virus partners, EBV, AAV, and retrovirus. Curr Gene Ther. 2004;4:385-408. 
45. Recchia A, Parks RJ, Lamartina S, et al. Site-specific integration mediated by a hybrid adenovirus/adeno-associated virus vector. Proc Natl Acad Sci U S A. 1999;96:2615-2620.

46. Feng M, Jackson WH Jr, Goldman CK, et al. Stable in vivo gene transduction via a novel adenoviral/retroviral chimeric vector. Nat Biotechnol. 1997; 15:866-870.

47. Kreuter J. Nanoparticulate systems for brain delivery of drugs. $A d v$ Drug Deliv Rev. 2001;47:65-81.

48. Wong HL, Wu XY, Bendayan R. Nanotechnological advances for the delivery of CNS therapeutics. Adv Drug Deliv Rev. 2012;64:686-700.

49. Bhaskar S, Tian F, Stoeger T, et al. Multifunctional Nanocarriers for diagnostics, drug delivery and targeted treatment across blood-brain barrier: perspectives on tracking and neuroimaging. Part Fibre Toxicol. 2010;7:3.

50. Kabanov AV, Batrakova EV, Alakhov VY. Pluronic block copolymers for overcoming drug resistance in cancer. Adv Drug Deliv Rev. 2002;54:759-779.

51. Sabatier JM, Vives E, Mabrouk K, et al. Evidence for neurotoxic activity of tat from human immunodeficiency virus type 1. J Virol. 1991;65:961-967.

52. Kanwar JR, Sriramoju B, Kanwar RK. Neurological disorders and therapeutics targeted to surmount the blood-brain barrier. Int $J$ Nanomedicine. 2012;7:3259-3278.

53. Pardridge WM, Kang YS, Buciak JL, et al. Human insulin receptor monoclonal antibody undergoes high affinity binding to human brain capillaries in vitro and rapid transcytosis through the blood-brain barrier in vivo in the primate. Pharm Res. 1995;12:807-816.

54. Zhang P, Hu L, Yin Q, Feng L, Li Y. Transferrin-modified c[RGDfK]paclitaxel loaded hybrid micelle for sequential blood-brain barrier penetration and glioma targeting therapy. Mol Pharm. 2012;9:1590-1598.

55. Hoar TP, Schulman JH. Transparent water-in-oil dispersion: the oleopathic hydro-micelle. Nature. 1943; 152:102-103.

56. Lawrence MJ, Rees GD. Microemulsion-based media as novel drug delivery systems. Adv Drug Deliv Rev. 2000;45:89-121.

57. Pardridge WM. Vector-mediated drug delivery to the brain. Adv Drug Deliv Rev. 1999;36:299-321.

58. Soni V, Kohli DV, Jain SK. Transferrin-conjugated liposomal system for improved delivery of 5-fluorouracil to brain. J Drug Target. 2008;16:73-78.

59. Blasi P, Giovagnoli S, Schoubben A, et al. Solid lipid nanoparticles for targeted brain drug delivery. Adv Drug Deliv Rev. 2007;59:454-477.

60. Anabousi S, Bakowsky U, Schneider M, et al. In vitro assessment of transferrin-conjugated liposomes as drug delivery systems for inhalation therapy of lung cancer. Eur J Pharm Sci. 2006;29:367-374.

61. Hatakeyama H, Akita H, Maruyama K, et al. Factors governing the in vivo tissue uptake of transferrin-coupled polyethylene glycol liposomes in vivo. Int J Pharm. 2004;281:25-33.

62. Xie F, Yao N, Qin Y, et al. Investigation of glucose-modified liposomes using polyethylene glycols with different chain lengths as the linkers for brain targeting. Int J Nanomedicine. 2012;7:163-175.

63. Gupta B, Levchenko TS, Torchilin VP. TAT peptide-modified liposomes provide enhanced gene delivery to intracranial human brain tumor xenografts in nude mice. Oncol Res. 2007;16:351-359.

64. Rao KS, Reddy MK, Horning JL, et al. TAT-conjugated nanoparticles for the CNS delivery of anti-HIV drugs. Biomaterials. 2008;29:4429-4438.

65. Shilo M, Motiei M, Hana P, et al. Transport of nanoparticles through the blood-brain barrier for imaging and therapeutic applications. Nanoscale. 2014;6:2146-2152.

66. Gao JQ, Lv Q, Li LM, Tang XJ, Li FZ, Hu YL, Han M. Glioma targeting and blood-brain barrier penetration by dual-targeting doxorubincin liposomes. Biomaterials. 2013;34:5628-5639.

67. Dechy-Cabaret O, Martin-Vaca B, Bourissou D. Controlled ringopening polymerization of lactide and glycolide. Chem Rev. 2004;104:6147-6176.

68. Yoo JY, Kim JM, Seo KS, et al. Characterization of degradation behavior for PLGA in various $\mathrm{pH}$ condition by simple liquid chromatography method. Biomed Mater Eng. 2005;15:279-288.
69. Tosi G, Costantino L, Rivasi F, et al. Targeting the central nervous system: in vivo experiments with peptide-derivatized nanoparticles loaded with Loperamide and Rhodamine-123. J Control Release. 2007;122:1-9.

70. Rawat M, Singh D, Saraf S, et al. Nanocarriers: promising vehicle for bioactive drugs. Biol Pharm Bull. 2006;29:1790-1798.

71. Zhang Z, Feng SS. The drug encapsulation efficiency, in vitro drug release, cellular uptake and cytotoxicity of paclitaxel-loaded poly(lactide)-tocopheryl polyethylene glycol succinate nanoparticles. Biomaterials. 2006;27:4025-4033.

72. Kanwar JR, Sun X, Punj V, et al. Nanoparticles in the treatment and diagnosis of neurological disorders: untamed dragon with fire power to heal. Nanomedicine. 2012;8:399-414.

73. Kulkarni SA, Feng SS. Effects of surface modification on delivery efficiency of biodegradable nanoparticles across the blood-brain barrier. Nanomedicine. 2011;6:377-394.

74. Pardridge WM, Wu D, Sakane T. Combined use of carboxyl-directed protein pegylation and vector-mediated blood-brain barrier drug delivery system optimizes brain uptake of brain-derived neurotrophic factor following intravenous administration. Pharm Res. 1998;15: 576-582.

75. Hu K, Li J, Shen Y, et al. Lactoferrin-conjugated PEG-PLA nanoparticles with improved brain delivery: in vitro and in vivo evaluations. J Control Release. 2009;134:55-61.

76. Kreuter J, Alyautdin RN, Kharkevich DA, et al. Passage of peptides through the blood-brain barrier with colloidal polymer particles (nanoparticles). Brain Res. 1995;674:171-174.

77. Steiniger SC, Kreuter J, Khalansky AS, et al. Chemotherapy of glioblastoma in rats using doxorubicin-loaded nanoparticles. Int J Cancer. 2004;109:759-767.

78. Wang CX, Huang LS, Hou LB, et al. Antitumor effects of polysorbate- 80 coated gemcitabine polybutylcyanoacrylate nanoparticles in vitro and its pharmacodynamics in vivo on C6 glioma cells of a brain tumor model. Brain Res. 2009;1261:91-99.

79. Gelperina S, Maksimenko O, Khalansky A, et al. Drug delivery to the brain using surfactant-coated poly(lactide-co-glycolide) nanoparticles: influence of the formulation parameters. Eur J Pharm Biopharm. 2010;74:157-163.

80. Pandey R, Sharma A, Zahoor A, et al. Poly (DL-lactide-co-glycolide) nanoparticle-based inhalable sustained drug delivery system for experimental tuberculosis. J Antimicrob Chemother. 2003;52: 981-986.

81. Guarnieri D, Falanga A, Muscetti O, et al. Shuttle-mediated nanoparticle delivery to the blood-brain barrier. Small. 2013;9:853-862.

82. Agarwal A, Agrawal H, Tiwari S, et al. Cationic ligand appended nanoconstructs: a prospective strategy for brain targeting. Int J Pharm. 2011;421:189-201.

83. Venishetty VK, Samala R, Komuravelli R, et al. beta-Hydroxybutyric acid grafted solid lipid nanoparticles: a novel strategy to improve drug delivery to brain. Nanomedicine. 2013;9:388-397.

84. Dhawan S, Kapil R, Singh B. Formulation development and systematic optimization of solid lipid nanoparticles of quercetin for improved brain delivery. J Pharm Pharmacol. 2011;63:342-351.

85. Chattopadhyay N, Zastre J, Wong HL, et al. Solid lipid nanoparticles enhance the delivery of the HIV protease inhibitor, atazanavir, by a human brain endothelial cell line. Pharm Res. 2008;25:2262-2271.

86. Gupta Y, Jain A, Jain SK. Transferrin-conjugated solid lipid nanoparticles for enhanced delivery of quinine dihydrochloride to the brain. J Pharm Pharmacol. 2007;59:935-940.

87. Wong HL, Bendayan R, Rauth AM, et al. Chemotherapy with anticancer drugs encapsulated in solid lipid nanoparticles. Adv Drug Deliv Rev. 2007;59:491-504.

88. Brioschi A, Zenga F, Zara GP, et al. Solid lipid nanoparticles: could they help to improve the efficacy of pharmacologic treatments for brain tumors? Neurol Res. 2007;29:324-330.

89. Kaur IP, Bhandari R, Bhandari S, et al. Potential of solid lipid nanoparticles in brain targeting. J Control Release. 2008;127:97-109. 
90. Sarin H, Kanevsky AS, Wu H, et al. Effective transvascular delivery of nanoparticles across the blood-brain tumor barrier into malignant glioma cells. J Transl Med. 2008;6:80.

91. Huang RQ, Qu YH, Ke WL, et al. Efficient gene delivery targeted to the brain using a transferrin-conjugated polyethyleneglycol-modified polyamidoamine dendrimer. FASEB J. 2007;21:1117-1125.

92. Dutta T, Jain NK. Targeting potential and anti-HIV activity of lamivudine loaded mannosylated poly (propyleneimine) dendrimer. Biochim Biophys Acta. 2007;1770:681-686.

93. Wolinsky JB, Grinstaff MW. Therapeutic and diagnostic applications of dendrimers for cancer treatment. Adv Drug Deliv Rev. 2008;60: 1037-1055.

94. Perez-Martinez FC, Guerra J, Posadas I, et al. Barriers to non-viral vector-mediated gene delivery in the nervous system. Pharm Res. 2011;28:1843-1858.

95. Kam NW, Liu Z, Dai H. Carbon nanotubes as intracellular transporters for proteins and DNA: an investigation of the uptake mechanism and pathway. Angew Chem Int Ed Engl. 2006;45:577-581.

96. Kostarelos K, Bianco A, Prato M. Promises, facts and challenges for carbon nanotubes in imaging and therapeutics. Nat Nanotechnol. 2009;4:627-633.

97. Petrov A, Audette GF. Peptide and protein-based nanotubes for nanobiotechnology. Wiley Interdiscip Rev Nanomed Nanobiotechnol. 2012;4:575-585.

98. Wu J, Yoon SH, Wu WM, et al. Synthesis and biological evaluations of brain-targeted chemical delivery systems of [Nva2]-TRH. J Pharm Pharmacol. 2002;54:945-950.

99. Brownlees J, Williams CH. Peptidases, peptides, and the mammalian blood-brain barrier. J Neurochem. 1993;60:793-803.

100. Wang PP, Frazier J, Brem H. Local drug delivery to the brain. Adv Drug Deliv Rev. 2002;54:987-1013.

101. Westphal M, Hilt DC, Bortey E, et al. A phase 3 trial of local chemotherapy with biodegradable carmustine (BCNU) wafers (Gliadel wafers) in patients with primary malignant glioma. Neuro Oncol. 2003;5:79-88.

102. Vukelja SJ, Anthony SP, Arseneau JC, et al. Phase 1 study of escalatingdose OncoGel (ReGel/paclitaxel) depot injection, a controlled-release formulation of paclitaxel, for local management of superficial solid tumor lesions. Anticancer Drugs. 2007;18:283-289.

103. Sheleg SV, Korotkevich EA, Zhavrid EA, et al. Local chemotherapy with cisplatin-depot for glioblastoma multiforme. J Neurooncol. 2002;60:53-59.

104. DiMeco F, Li KW, Tyler BM, et al. Local delivery of mitoxantrone for the treatment of malignant brain tumors in rats. $J$ Neurosurg. 2002;97:1173-1178

105. Greig NH. Optimizing drug delivery to brain tumors. Cancer Treat Rev. 1987;14:1-28.

106. Harbaugh RE, Saunders RL, Reeder RF. Use of implantable pumps for central nervous system drug infusions to treat neurological disease. Neurosurgery. 1988;23:693-698.

107. Scheld WM. Drug delivery to the central nervous system: general principles and relevance to therapy for infections of the central nervous system. Rev Infect Dis. 1989;11 Suppl 7:S1669-S1690.

108. Sladek JR Jr, Gash DM. Nerve-cell grafting in Parkinson's disease. J Neurosurg. 1988;68:337-351.

109. Leigh K, Elisevich K, Rogers KA. Vascularization and microvascular permeability in solid versus cell-suspension embryonic neural grafts. J Neurosurg. 1994;81:272-283.

110. Cunningham J, Pivirotto P, Bringas J, et al. Biodistribution of adeno-associated virus type- 2 in nonhuman primates after convection-enhanced delivery to brain. Mol Ther. 2008;16:1267-1275.

111. Bidros DS, Vogelbaum MA. Novel drug delivery strategies in neuro-oncology. Neurotherapeutics. 2009;6:539-546.

112. Chen MY, Lonser RR, Morrison PF, et al. Variables affecting convection-enhanced delivery to the striatum: a systematic examination of rate of infusion, cannula size, infusate concentration, and tissuecannula sealing time. J Neurosurg. 1999;90:315-320.

113. Neuwelt EA. Mechanisms of disease: the blood-brain barrier. Neurosurgery. 2004;54:131-140.
114. Kroll RA, Neuwelt EA. Outwitting the blood-brain barrier for therapeutic purposes: osmotic opening and other means. Neurosurgery. 1998;42:1083-1099.

115. Kroll RA, Pagel MA, Muldoon LL, et al. Improving drug delivery to intracerebral tumor and surrounding brain in a rodent model: a comparison of osmotic versus bradykinin modification of the blood-brain and/or blood-tumor barriers. Neurosurgery. 1998;43: 879-886.

116. Rapoport SI, Robinson PJ. Tight-junctional modification as the basis of osmotic opening of the blood-brain barrier. Ann N Y Acad Sci. 1986;481:250-267.

117. Kraemer DF, Fortin D, Doolittle ND, et al. Association of total dose intensity of chemotherapy in primary central nervous system lymphoma (human non-acquired immunodeficiency syndrome) and survival. Neurosurgery. 2001;48:1033-1040.

118. McAllister LD, Doolittle ND, Guastadisegni PE, et al. Cognitive outcomes and long-term follow-up results after enhanced chemotherapy delivery for primary central nervous system lymphoma. Neurosurgery. 2000;46:51-60.

119. Neuwelt EA, Barnett PA, Glasberg M, et al. Pharmacology and neurotoxicity of cis-diamminedichloroplatinum, bleomycin, 5-fluorouracil, and cyclophosphamide administration following osmotic blood-brain barrier modification. Cancer Res. 1983;43:5278-5285.

120. Cloughesy TF, Black KL. Pharmacological blood-brain barrier modification for selective drug delivery. $J$ Neurooncol. 1995;26:125-132.

121. Zhao YZ, Lu CT, Li XK, et al. Improving the cardio protective effect of aFGF in ischemic myocardium with ultrasound-mediated cavitation of heparin modified microbubbles: preliminary experiment. J Drug Target. 2012;20:623-631.

122. Zhao YZ, Gao HS, Zhou ZC, et al. Experiment on the factors for enhancing the susceptibility of cancer cells to chemotherapeutic drug by ultrasound microbubbles. J Drug Target. 2010;18:430-437.

123. Zhao YZ, Lu CT, Mei XG. Optimization of the preparation of sonogenic phospholipids-based microbubbles by using central composite experimental design and response surface methodology. Yао Хие Хие Вао. 2008;43:862-867.

124. Guthkelch AN, Carter LP, Cassady JR, et al. Treatment of malignant brain tumors with focused ultrasound hyperthermia and radiation: results of a phase I trial. J Neurooncol. 1991;10:271-284.

125. Pernot M, Aubry JF, Tanter M, et al. High power transcranial beam steering for ultrasonic brain therapy. Phys Med Biol. 2003;48: 2577-2589.

126. Aubry JF, Tanter M, Pernot M, et al. Experimental demonstration of noninvasive transskull adaptive focusing based on prior computed tomography scans. J Acoust Soc Am. 2003;113:84-93.

127. Hynynen K, Clement GT, McDannold N, et al. 500-element ultrasound phased array system for noninvasive focal surgery of the brain: a preliminary rabbit study with ex vivo human skulls. Magn Reson Med. 2004;52:100-107.

128. Thorne RG, Frey WH. Delivery of neurotrophic factors to the central nervous system: pharmacokinetic considerations. Clin Pharmacokinet. 2001;40:907-946.

129. Illum L. Transport of drugs from the nasal cavity to the central nervous system. Eur J Pharm Sci. 2000;11:1-18.

130. Mathison S, Nagilla R, Kompella UB. Nasal route for direct delivery of solutes to the central nervous system: fact or fiction? J Drug Target. 1998;5:415-441.

131. Sakane T, Akizuki M, Taki Y, et al. Direct drug transport from the rat nasal cavity to the cerebrospinal fluid: the relation to the molecular weight of drugs. J Pharm Pharmacol. 1995;47:379-381.

132. Eskandari S, Varshosaz J, Minaiyan M, Tabbakhian M. Brain delivery of valproic acid via intranasal administration of nanostructured lipid carriers: in vivo pharmacodynamic studies using rat electroshock model. Int J Nanomedicine. 2011;6:363-371.

133. Jogani V, Jinturkar K, Vyas T, et al. Recent patents review on intranasal administration for CNS drug delivery. Recent Pat Drug Deliv Formul. 2008;2:25-40. 
International Journal of Nanomedicine

Dovepress

\section{Publish your work in this journal}

The International Journal of Nanomedicine is an international, peerreviewed journal focusing on the application of nanotechnology in diagnostics, therapeutics, and drug delivery systems throughou the biomedical field. This journal is indexed on PubMed Central, MedLine, CAS, SciSearch ${ }^{\circledR}$, Current Contents ${ }^{\circledR} /$ Clinical Medicine,
Journal Citation Reports/Science Edition, EMBase, Scopus and the Elsevier Bibliographic databases. The manuscript management system is completely online and includes a very quick and fair peer-review system, which is all easy to use. Visit http://www.dovepress.com/ testimonials.php to read real quotes from published authors.

Submit your manuscript here: http://www.dovepress.com/international-journal-of-nanomedicine-journal 